\author{
ROCZNIKI HUMANISTYCZNE \\ Tom LXIX, zeszyt $6-2021$ \\ ZESZYT SPECJALNY \\ DOI: https://doi.org/10.18290/rh21696s-7
}

MONIKA ŁAKUTA

\title{
EL DESARROLLO DE LA COMPETENCIA CULTURAL EN EL ENTORNO VIRTUAL - TEORÍA Y PRÁCTICA
}

\section{INTRODUCCIÓN}

Hoy en día la cultura ocupa un lugar fundamental en el proceso de la enseñanza y del aprendizaje de una lengua extranjera. Con la anterioridad al enfoque comunicativo, no había un lugar específico en el currículum de lenguas extranjeras para la enseñanza de los contenidos culturales y la enseñanza de una lengua extranjera se concebía antes más bien como una práctica puramente lingüística, centrada en la gramática. El cambio del papel de la cultura en el proceso didáctico de una lengua extranjera lo trajo consigo la aparición del enfoque comunicativo en los años 70 del siglo XX. A partir de entonces, el componente cultural se integra dentro de la competencia comunicativa como cultura para entender, actuar e interactuar comunicativamente. Uno de los primeros en definir el concepto de la competencia comunicativa fue Dell $\mathrm{H}$. Hymes. Según Hymes la competencia comunicativa es la capacidad de formular enunciados gramaticalmente correctos y socialmente adecuados. Este autor definió cuatro criterios para describir las formas de comunicación:

- si (y en qué medida) es formalmente posible,

- si (y en qué medida) es factible según los medios de actuación disponibles,

- si (y en qué medida) es apropiada al contexto en que se utiliza,

- si (y en qué medida) es usada efectivamente.

Mgr MoniKa ŁaKUTA - asystent w Katedrze Akwizycji i Dydaktyki Języków Instytutu Językoznawstwa Katolickiego Uniwersytetu Lubelskiego Jana Pawła II; adres do korespondencji: Katolicki Uniwersytet Lubelski Jana Pawła II, Al. Racławickie 14, 20-950 Lublin; e-mail: monika.lakuta@kul.lublin.pl; ORCID: https://orcid.org/0000-0002-9679-2799. 
Michael Canale (1983) denominó la competencia comunicativa como un conjunto de cuatro competencias interrelacionadas: la competencia lingüística, sociolingüística, estratégica y discursiva. A estas cuatro competencias, Jan van Ek agregó la competencia sociocultural y la competencia social. Según Dimitrinka G. Níkleva:

Los enfoques comunicativos vienen destacando desde sus inicios la importancia de la cultura en la enseñanza- aprendizaje de la lengua. No cabe ninguna duda de que el uso de la lengua requiere una competencia sociocultural, de que la adecuación no es solo lingüística, sino también sociolingüística y cultural. Saber usar una lengua implica conocer sus referentes culturales, implica saber hacer y saber ser, saber comportarse y saber interpretar el comportamiento de los demás. (165)

Sin duda, hoy en día, la cultura desempeña el mismo papel que la lengua en el proceso de la enseñanza, ya que la lengua transmite la cultura y ambas funcionan inseparablemente en el proceso de comunicación. No obstante, resulta imposible que la enseñanza de la cultura sea idéntica a la enseñanza de la lengua porque en la enseñanza de la lengua predomina la imitación, la asimilación y la automatización de la información. Por el contrario, gracias al enfoque intercultural la enseñanza de la cultura se centra en comprender y comparar la cultura extranjera con la cultura materna. Por consiguiente, han de mencionarse tres culturas: la cultura que se descubre (la del otro), la que se vuelve a descubrir (la suya) y la que forman juntas.

Para poder identificar los elementos culturales y pensar en cómo y qué cultura se debe enseñar, es conveniente definir la cultura y tomar en consideración las exigencias del Plan curricular del Instituto Cervantes, las del Marco Común Europeo de Referencia para las Lenguas y los modelos elaborados por Byram y Moran.

En el presente trabajo se mostrarán también algunos elementos culturales analizados en clase virtual (en la plataforma Office 365) de destrezas integradas y de expresión escrita, en grupos de veintiséis personas, con los alumnos de nivel umbral del primer curso universitario mediante algunas actividades de la lengua, tomando en consideración los desafíos que plantea tanto a los estudiantes como a los docentes el trabajo en entornos virtuales. Asimismo, se incluirán ejemplos de las herramientas utilizadas en clase a la hora de trabajar los contenidos culturales, todos elegidos por el docente e integrados en las actividades de la lengua, pensando en el equilibrio entre la cultura española y la latinoamericana. 


\section{EL CONCEPTO DE LA INTERCULTURALIDAD Y LA FORMACIÓN DEL ESTUDIANTE INTERCULTURAL}

No se puede cuestionar que es imposible hablar de un estudiante intercultural sin pensar en cómo definir la interculturalidad. Según el Plan curricular del Instituto Cervantes es un concepto basado en la cultura y sociocultura. La cultura hace referencia a los referentes culturales, entre los cuales se encuentran tanto las características geográficas, políticas, económicas, etc. de los países hispanohablantes, como su patrimonio histórico y cultural. Todo ello se puede denominar como el conocimiento factual, enciclopédico.

La sociocultura abarca el conocimiento basado en el modo de vivir, la experiencia, los aspectos cotidianos, la identidad colectiva, las relaciones personales, la organización social, etc. que aparecen en una sociedad determinada. Por eso, son los saberes y comportamientos socioculturales.

La definición del concepto de la interculturalidad no sería completa sin definición de las habilidades y actitudes interculturales. Sin lugar a dudas, son las que permiten a los aprendientes acercarse a las otras culturas y, en el caso de español lengua extranjera, a la cultura de los países hispanohablantes, desde una perspectiva intercultural. Lo que ocupa el lugar primordial en este contexto es la comprensión, la aceptación, etc. de las bases culturales y socioculturales comunes, compartidas por los miembros de las comunidades a las que tienen acceso los alumnos. Es necesario mencionar aquí la memoria histórica, los valores, las creencias, etc. que aparecen en la literatura, en el cine y las artes plásticas, entre otros.

Al hablar de la interculturalidad es incuestionable la necesidad de reflexionar sobre cómo describir y definir al alumno intercultural y cómo formarlo. Según el Plan curricular del Instituto Cervantes se trata de una persona capaz de identificar, a través de la lengua, los aspectos relevantes de la nueva cultura y, al mismo tiempo, desarrollar la sensibilidad de crear unos puentes entre la cultura de origen y la cultura nueva (31). Para poder lograrlo es imprescindible una actitud abierta y el conocimiento de los referentes culturales y de las normas.

De cualquier modo, el presente estudio sería incompleto sin analizar las habilidades interculturales propuestas por Byram (Teaching and Assessing 34), que pueden aparecer en diferentes campos. Entre ellas, en primer lugar, conviene mencionar los conocimientos o lo que se llama el saber (knowledge), basados en el conocimiento del mundo. Los siguen las actitudes o facultades (saber ser/attitudes) para ser conscientes de las diferencias culturales. En tercer 
lugar, se encuentran las habilidades (saber hacer/skills), con las que uno cuenta para observar, analizar, comunicarse y, de esta manera, conocer otra cultura.

La formación de la competencia comunicativa se pone en marcha y se realiza gracias a las operaciones denominadas como modelo de experiencia cultural (Cultural Knowings Framework), descrito por Patrick R. Moran. Lo forman operaciones basadas en los siguientes elementos:

- Knowing About: recoger la sabiduría e información indispensables sobre la lengua y la cultura meta;

- Knowing How: aprender a actuar adecuadamente en una situación concreta;

- Knowing Why: descubrir y comprender el sistema de valores, sabiduría popular, modos de actuar específicos para cada cultura;

- Knowing Oneself: reflexionar sobre el sistema de valores de su propia cultura.

El modelo de experiencia cultural indica que, al aprender una lengua extranjera, los estudiantes tienen que pasar por un proceso de formación bastante complejo para reflexionar sobre información lingüística y cultural que se encuentran durante el aprendizaje de una lengua extranjera y compararla con su lengua materna, y poder desarrollar su propia competencia comunicativa y cultural activa y conscientemente.

\section{3. ¿QUÉ CULTURA ENSEÑAR?}

Queda claro que, al analizar la competencia cultural, conviene reflexionar sobre cómo comprender la cultura y, ante todo, qué cultura enseñar y cómo incorporarla en el programa de clases. Si no se trata de una clase dedicada únicamente a la enseñanza de la cultura, es imprescindible reflexionar sobre qué contenidos culturales enseñar y qué criterios aplicar a la hora de elegirlos.

Lourdes Miquel y Neus Sans elaboraron una definición bastante amplia de cultura, al relacionar las definiciones propuestas por Harris y Porcher:

Resumiendo a Harris (1990) podríamos decir que la cultura es un conjunto aprendido/adquirido socialmente de tradiciones, estilos de vida y de modos pautados y repetitivos de pensar, sentir y actuar. Definición a la que podríamos añadir la de Porcher (1986): "Toda cultura es un modo de clasificación, es la ficha de identidad de una sociedad, son los conocimientos de los que dispone; son las opiniones (filosóficas, morales, estéticas...) fundadas más en convicciones que en un saber". Y, para completar este marco teórico, nos permitimos añadir que la cultura es, ante todo, una 
adhesión afectiva, un cúmulo de creencias que tienen fuerza de verdad y que marcan, en algún sentido, cada una de nuestras actuaciones como individuos miembros de una sociedad. (Miquel y Sans 328)

Según la clasificación de Miquel y Sans se pueden mencionar tres categorías de la cultura:

- La Cultura con mayúscula, la que abarca la noción tradicional de la cultura, el saber artístico y literario, el saber de carácter geográfico, histórico y político, etc.

- La cultura con minúscula, conocida como cultura social y las costumbres, tradiciones, ritos y usos propios de cada sociedad. Esta cultura engloba también la comunicación no verbal, la pragmática sociocultural, la gastronomía, el modo de vestir y actuar en determinadas situaciones, etc.

- La kultura (con "k") que comprende el saber, las costumbres o los usos que difieren del estándar cultural y no son compartidos por todos los hablantes, como el argot.

Todos estos elementos mencionados anteriormente constituyen una parte de la competencia sociocultural. Es la competencia que un alumno debería adquirir inseparablemente de la competencia comunicativa mientras aprende un idioma y es el profesorado el responsable de introducir el componente cultural en el aula y acercarlo a los aprendientes.

\section{EL COMPONENTE CULTURAL EN EL AULA VIRTUAL DE ELE}

Tal como se ha mencionado anteriormente, no cabe la menor duda de que la formación cultural constituye uno de los principios de la didáctica de lenguas, quedará por analizar cómo se realiza en las actividades de la lengua en el entorno virtual, tomando en consideración las dificultades que encuentran tanto los profesores como los estudiantes durante las clases en línea. Se trata, ante todo, de la falta de respuestas no verbales del alumnado, de las dificultades a la hora de mantener el nivel de atención y motivación del alumnado. Tampoco se puede olvidar lo difícil que es seguir el progreso de los estudiantes y evaluar sus conocimientos.

\subsection{La cultura como componente de un ejercicio de comprensión}

Se empleó la cultura en las actividades de la lengua relacionadas con leer y escuchar. Los estudiantes, de primer curso y nivel A2/B1, usaron las 
competencias y los procesos lingüísticos de comprensión auditiva y lectora, por ejemplo, para aprender algunos conceptos, informarse sobre algo, etc.

Como actividades de comprensión auditiva se usaron en clase en línea, entre otros, ejercicios tales como: escuchar avisos, programas de radio y de televisión, canciones para captar la idea general, para obtener información específica y seleccionar algunos detalles. Se incluyeron grabaciones con varios acentos, los de distintas regiones de España y los de Argentina, Uruguay, Colombia, México y Perú.

Ha habido muchos casos en los que, a la hora de trabajar la interculturalidad en las actividades de comprensión de lectura, se ha recurrido al uso de material que incluía información cultural perteneciente a la Cultura con mayúscula o a la cultura con minúscula.

Se trabajaron textos con algunas tareas que iban más allá de unos ejercicios tradicionales de este tipo de actividad de la lengua, tales como captar la idea general de un artículo, informarse sobre algo, etc. Por ejemplo, al analizar el tema de la comida, se pidió a los estudiantes que reflexionaran sobre los hábitos de comer en España y los suyos propios después de leer un texto relacionado con este tema. Este tipo de actividad se presta bien a la inserción de la interculturalidad en el aula, despertando el interés de los aprendientes por lo ajeno a su cultura y despertando la consciencia sobre las similitudes y las diferencias entre su propia cultura y la cultura de la lengua meta.

Entre las actividades de comprensión, conviene mencionar las actividades de comprensión audiovisual, en la cual se recibe información por dos canales, el auditivo y el visual, y cuya comprensión resulta más fácil gracias a que «está semantizada, es decir, asociada a unos códigos que se dan cita en el discurso fílmico; no solo la imagen, también los diálogos, los sonidos, la música, los signos gráficos, etc.» (Montoussé 75).

Se incluyeron en clase actividades tales como ver un vídeo subtitulado, cortometrajes, etc. En muchas ocasiones se optó por los videos de YouTube. Se emplearon herramientas tales como Clideo para editar videos e insertar en ellos ejercicios de comprensión (preguntas de opción múltiple y de respuesta corta). De esta manera, se trabajó, por ejemplo, una receta de cocina. Los estudiantes vieron un video sobre cómo preparar el gazpacho, respondieron a una serie de preguntas que aparecían durante el visionado y, a continuación, explicaron cómo se preparaba su plato favorito. 


\subsection{La cultura como componente de un ejercicio de expresión}

La información de carácter cultural se incluyó también en las actividades de la lengua, relacionadas con la expresión oral o escrita, con el propósito de alcanzar tales objetivos como informar, dar a conocer, expresar ideas o sentimientos, etc. Se trabajaron varias actividades comunicativas, en las que los participantes se iban turnando en la producción y recepción del discurso.

Entre las actividades de expresión oral se trabajaron, entre otras, instrucciones, diálogos, etc.

Las prácticas sociales de comunicación se trabajaron, por ejemplo, en las actividades que consisten en la redacción de mensajes cortos (un correo electrónico) o los comportamientos sociales (presentar, saludar, invitar, etc.).

Para mejorar los procesos de expresión, se recurrió a una serie de estrategias comunicativas propias de la expresión, entre las cuales cabe mencionar la atención al destinatario (selección del registro y estilo adecuados), estrategias de compensación tales como parafrasear o autocorregirse.

Tal como en el caso de los ejercicios de comprensión, en el caso de los ejercicios de producción también se incluyeron aspectos culturales albergados en la Cultura con mayúscula o la cultura con minúscula. Por ejemplo, al hablar de la ropa, los estudiantes hicieron una búsqueda del origen de las alpargatas y se informaron sobre algunos diseñadores de moda, por ejemplo, Cristóbal Balenciaga, Óscar de la Renta, Ágatha Ruiz de la Prada y Manolo Blahnik, entre otros. Los estudiantes presentaron su opinión sobre algunos proyectos de los diseñadores mencionados anteriormente y los contrastaron con su estilo personal. Gracias a esta actividad, los estudiantes tuvieron la oportunidad de descubrir el mercado nacional de moda y algunas marcas locales reconocidas a nivel mundial.

Otra de las actividades propuestas, se basaba en la descripción de los personajes de las obras de la autoría de Fernando Botero. A la hora de practicar la descripción del aspecto físico se usaron fotos que representaban las esculturas y la pintura del artista colombiano. Con el mismo propósito se usaron en clase las fotografías de los moáis de la Isla de la Pascua.

\subsection{La cultura como componente de un ejercicio de interacción}

Los elementos culturales se incluyeron también a la hora de trabajar las actividades de interacción. En la mayoría de los casos, se trataba de actividades orales, en tiempo real, gracias al aprovechamiento de la función de habitaciones en Teams, en la plataforma Office 365 en las que dos o más 
estudiantes cambiaban sus papeles de emisor y receptor de mensajes y construían una conversación, cooperando entre ellos. Algunos ejemplos de actividades de interacción oral en clase fueron: discusión informal, entrevista, negociación y debate. Para incentivar la interacción se les propuso a los estudiantes la grabación de una cibercharla y esta actividad gozó de éxito entre el alumnado.

Los elementos culturales que se usaron, ante todo, como imput en clase, de manera parecida a las actividades de los apartados anteriores, hicieron referencia a la Cultura con mayúscula y la cultura con minúscula.

De entre las actividades hechas en clase, se optó por los proyectos de Antonio Gaudí o las ruinas del Imperio Inca para negociar el tipo de actividades incluidas en el itinerario de viaje. Otro ejemplo de recurrir a la cultura es el uso de música. Son numerosas las ocasiones en las que se ha usado música en clase, tanto para trabajar a base de canciones en las actividades de comprensión, como en las de interacción. Por ejemplo, para hablar sobre los viajes en el pasado se usó la canción de los años 70 del grupo Fórmula $\mathrm{V}$ titulada "Eva María".

\section{CONCLUSIONES}

A día de hoy, la enseñanza de idiomas se encuentra en un momento del pleno desarrollo y queda muy claro que no puede enfocarse solamente en los contenidos puramente lingüísticos. En el proceso de la adquisición de una lengua extranjera es de suma importancia la enseñanza de la cultura, pero resulta difícil en el entorno virtual, sobre todo en cuanto a los gestos, comportamientos, rituales lingüísticos, que tienen igual importancia que las palabras pronunciadas en el acto de comunicación.

A base de la práctica descrita anteriormente, se puede constatar que los contenidos culturales nunca se han usado solamente como material para memorizar. Si hubiera sido así, su uso en clase habría resultado contraproducente. Por consiguiente, se usaron como un punto de partida para hacer a los estudiantes reflexionar sobre la cultura y contrastar la cultura de los alumnos con la extranjera. Su valor es innegable, aunque hay que ser consciente de los límites provocados por los requerimientos y la naturaleza de la enseñanza en línea.

Todas las actividades propuestas durante el curso, tanto de destrezas integradas como de expresión escrita, les permitieron a los estudiantes conocer los 
rituales, comportamientos y las prácticas sociolingüísticas propias de la cultura meta, pero al mismo tiempo, evidentemente, han sido un punto de partida para reflexionar sobre la cultura de origen. Los estudiantes tuvieron la oportunidad de aprender sobre la historia, el patrimonio cultural (monumentos históricos), la cultura profesional y la vida cotidiana (menús, medios de transporte). También aprendieron a desenvolverse adecuadamente en el entorno profesional (hablar por teléfono) y las situaciones de la vida cotidiana (elegir un plato en un restaurante, quedar con amigos, etc.). Los conocimientos adquiridos en clase se verificaron en las pruebas de expresión oral, escrita y de interacción. Sin embargo, es evidente que resultó mucho más difícil hacer todo ello en el entorno virtual, dado el límite de interacción humana, algunos problemas técnicos y la dificultad de un gran número de estudiantes a la hora de hablar en público, mucho más fuerte, a través de la pantalla del ordenador.

La adquisición de conocimientos interculturales se basa, sobre todo en el nivel umbral, en cómo el profesor emplee el contenido cultural en el aula. Del profesor depende cómo aprovechar la información cultural con el fin de crear un mejor entendimiento, aprecio hacia lo suyo y lo del otro, y en consecuencia, enseñar la tolerancia. Del profesorado depende también una selección adecuada del contenido cultural, dada la riqueza y variedad del mundo hispanohablante. Por ello, la labor del docente se centró en intentar captar la atención del alumno, de animarlo a que hiciera comparaciones culturales, pero también en explicarle todo lo que pudiera contribuir al desarrollo intercultural del alumnado. Se podría constatar que todas las actividades realizadas en clase han sido solo un tipo de iniciación a la cultura del mundo hispanohablante.

\section{OBRAS CITADAS}

Areizaga, Elisabet. «El componente cultural en la enseñanza de lenguas: elementos para el análisis y la evaluación del material didáctico», Cultura y educación, vol. 14, 2002, págs. 161-175.

Byram, Michael. Teaching and Assessing Intercultural Communicative Competence. Multilingual Matters, 1997.

Byram, Michael. «Acquiring Intercultural Competence. A review of Learning Theories». Intercultural Competence. A New Challenge for Language Teachers and Trainers in Europe, ed. Lies Sercu, Centre for Languages and Intercultural Studies, Aalborg UP, 1995, págs. 53-69.

Canale, Michael. «De la competencia comunicativa a la pedagogía comunicativa del lenguaje». Competencia comunicativa. Documentos básicos en la enseñanza de lenguas extranjeras, ed. Miquel Llobera et al., Edelsa, 1995, págs. 63-83. 
Consejo de Europa. Marco de referencia europeo para el aprendizaje, la enseñanza y la evaluación de lenguas. Council for Cultural Cooperation, Education Committee Modern Language Division, 2001.

Consejo de Europa. Marco común de referencia europeo para las lenguas: aprendizaje, enseñanza, evaluación. Secretaría General Técnica del MEC, Anaya e Instituto Cervantes, 2002.

Ek, Jan van. Objectives for Foreign Language Learning. Vol. 1, Council of Europe, 1986.

Harris, Marvin. Antropología cultural. Alianza Editorial, 1990.

Hymes, D. H. «Acerca de la competencia comunicativa». Competencia comunicativa. Documentos básicos en la enseñanza de lenguas extranjeras, ed. Miquel Llobera et al., Edelsa, 1995, págs. 27-47.

Instituto Cervantes. Plan curricular del Instituto Cervantes. Editorial Biblioteca Nueva S. L., 2006.

Komorowska, Hanna. Metodyka nauczania języków obcych. Fraszka Edukacyjna, 1999.

Miquel, Lourdes, y Neus Sanz. «El componente cultural: un ingrediente más en las clases de lengua.», RedELE, 1992, págs. 15-21.

Montoussé Vega, Juan Luis. «¿Qué hago con esta película?: usos y valor del cine en el aula de ELE», Instituto Cervantes, 2012 [en línea], cvc.cervantes.es/ensenanza/biblioteca_ele/publicaciones centros/PDF/argel_2012/07_montousse.pdf. Consultado el 9 de mayo de 2021.

Moran, Patrick. Teaching Culture: Perspectives in Practice. Foreign Language Teaching and Research Press, 2001.

Níkleva, Dimitrinka G. «La competencia intercultural y el tratamiento de contenidos culturales en manuales de español como lengua extranjera», Revista Española de Lingüística Aplicada, vol. 25, 2012, págs. 165-187.

Porcher, Louis et al. La civilisation, Clé International, 1988.

Robles, Sara. «Lengua en la cultura y cultura en la lengua», Actas del XIII Congreso Internacional de ASELE, 2002, págs. 720-730.

\section{EL DESARROLLO DE LA COMPETENCIA CULTURAL EN EL ENTORNO VIRTUAL - TEORÍA Y PRÁCTICA}

\section{$\mathrm{R}$ e s u m e n}

Este artículo trata el tema de la competencia cultural en la didáctica del español como lengua extranjera en el entorno virtual. En él se presenta el término cultura, se habla de la interculturalidad y se muestran unos ejemplos prácticos de cómo enseñar la cultura en el aula virtual. El objetivo del artículo es diferenciar los tipos de cultura y analizar las distintas maneras de usarlos en el aula de español como lengua extranjera al trabajar con los estudiantes del nivel umbral.

Palabras clave: cultura; español como lengua extranjera; didáctica del español; componente cultural; entorno virtual. 


\section{ROZWÓJ KOMPETENCJI KULTUROWYCH \\ W ŚRODOWISKU WIRTUALNYM - TEORIA I PRAKTYKA}

\section{Streszczenie}

W artykule poruszono problematykę kompetencji kulturowej w nauczaniu języka hiszpańskiego jako obcego w formie nauczania zdalnego. Poddano analizie termin kultury, międzykulturowości i omówiono kilka praktycznych przykładów nauczania kultury w wirtualnej klasie. Celem artykułu jest analiza różnych sposobów wykorzystania elementów kulturowych na zajęciach $\mathrm{z}$ języka hiszpańskiego jako języka obcego $\mathrm{w}$ pracy ze studentami rozpoczynającym naukę tego języka $(\mathrm{A} 1-\mathrm{A} 2 / \mathrm{B} 1)$.

Słowa kluczowe: kultura; hiszpański jako język obcy; dydaktyka hiszpańskiego; komponent kulturowy; nauczanie zdalne.

\section{THE DEVELOPMENT OF CULTURAL COMPETENCES IN A VIRTUAL ENVIRONMENT: THEORY AND PRACTICE}

\section{S u m m a ry}

This article deals with the issue of cultural competence in the teaching of Spanish as a foreign language in the virtual environment. It presents the term 'culture', deals with interculturality, and shows some practical examples of how to teach culture in the virtual classroom. The objective here is to differentiate the types of culture and analyze the different ways to use them in Spanish as a foreign language classroom when working with students at the threshold level (A1-A2/B1).

Keywords: culture; Spanish as foreign language; teaching Spanish; cultural component; virtual environment. 